\title{
Electrochemical Redox Mechanism of Polyaniline Analyzed by X-ray Photoelectron Spectroscopy
}

\author{
Katsuaki OKABAYASHI*, Shi-aki HYODO, Katsushi ABE and Takashi YOSHIDA
}

Received January 30, 1989 ; Accepted May 15, 1989

\begin{abstract}
X-ray photoelectron spectroscopy (XPS) was used to characterize the molecular structure and redox mechanism of polyaniline (PAn) in non-aqueous and aqueous solutions. It was found that the content of cationized nitrogen and perchlorate anion in the polymer increased on oxidation in the non-aqueous solution. This indicates that the redox of PAn in the non-aqueous solution is accompanied by redox of the nitrogen atom whose positive charge is compensated by the anion. On the other hand, the content of the cationized nitrogen and the anion increased on reduction in the aqueous solution. This XPS data shows that electrochemical redox in the aqueous solution affects the chemical acid-base equilibrium of the polymer.
\end{abstract}

\section{INTRODUCTION}

Polyaniline (PAn) has recently attracted considerable interest as an electrode material for secondary batteries because of its high chemical stability, electrochemical reversibility and discharge capacity (1-4). Although many studies concerning the chemical structure or the redox mechanism of PAn have been carried out using various methods (5-8), the conformation change during the redox process has not been clearly observed. In this paper we present XPS results concerning PAn in various oxidation states in non-aqueous and aqueous acid solutions. The molecular structure and the redox mechanism of PAn are discussed on the basis of the XPS information relating to the electronic structure and elemental composition of the compound.

\section{EXPERIMENTAL}

\section{1 Sample preparation}

We prepared five types of PAn for the XPS measurements. The procedures for preparation of each sample are described as follows.

As-Polymerized PAn (PAn1): A thin film of PAn1 was electrochemically synthesized and deposited onto a platinum plate (surface area $2 \mathrm{~cm}^{2}$ ) in a $2 \mathrm{M} \mathrm{HClO}$ aqueous solution containing $1 \mathrm{M}$ aniline at a current density of $3 \mathrm{~mA} / \mathrm{cm}^{2}$. The total quantity of charge passed was $10 \mathrm{C} / \mathrm{cm}^{2}$. The $\mathrm{film}$ so obtained was immersed in distilled water and dried at $100^{\circ} \mathrm{C}$ under a dynamic vacuum for 12 hours.

Toyota Central Research \& Development Laboratories, Inc.

Nagakute-cho, Aichi-gun, Aichi-ken, 480-11 (Japan)

Key Words: Polyaniline, Redox, XPS, Battery 
PAn1 Reduced in Non-Aqueous Solution (PAn2): PAn2 was prepared by reducing PAn1 in a non-aqueous $1 \mathrm{M} \mathrm{LiClO} 4$ /propylene carbonate at a current density of $1 \mathrm{~mA} / \mathrm{cm}^{2}$ until the total charge passed reached $1.5 \mathrm{c} / \mathrm{cm}^{2}$. These values of current and total charge were also subsequently used for all other sample preparations. The film was immersed in methanol and dried under a dynamic vacuum for 3 hours.

PAn1 Oxidized in Non-Aqueous Solution (PAn3): PAn3 was prepared by oxidizing PAn1 under the same condition as PAn2.

PAn1 Reduced in Aqueous Acid Solution (PAn4): PAn4 was prepared by the same procedure as PAn2 except that it was reduced in $1 \mathrm{M} \mathrm{HClO}_{4}$ aqueous solution.

PAn1 Oxidized in Aqueous Acid Solution (PAn5): PAn5 was also prepared by the same procedure as PAn3 except that it was oxidized in the aqueous solution.

\subsection{XPS measurements}

XPS measurements were performed using a Shimazu ESCA650B, employing Mg K $\alpha$ radiation ( $8 \mathrm{kV}, 36 \mathrm{~mA})$. The vacuum chamber pressure was lower than $10^{-7}$ Torr. The samples were removed from the platinum substrate for analysis in the form of a powder coated onto double-sided tape.

\section{RESULTS}

\section{1 Peak positions and relative elemental compositions}

Charge build-up shifts in the observed core level binding energies were corrected by fixing the binding energy of $\mathrm{C}(1 \mathrm{~s})$ to $285.0 \mathrm{eV}$ in accordance with known results in the literature. The observed $\mathrm{C}(1 \mathrm{~s})$ peaks as well as the corrected $\mathrm{N}(1 \mathrm{~s}), \mathrm{Cl}(2 \mathrm{p})$ and $0(1 \mathrm{~s})$ peaks of each sample are listed in Table 1.

Table 1 XPS binding energies of each element ${ }^{\mathfrak{A}}$

\begin{tabular}{lccccc}
\hline $\begin{array}{l}\text { poly- } \\
\text { aniline }\end{array}$ & $\mathrm{C}(1 \mathrm{~s})$ & $\begin{array}{c}\text { charge build-up } \\
\text { shift }\end{array}$ & $\mathrm{N}(1 \mathrm{~s})$ & $\mathrm{Cl}(2 \mathrm{p})$ & $0(1 \mathrm{~s})$ \\
\hline PAn1 & 284.0 & -1.0 & 400.1 & 208.1 & 532.7 \\
PAn2 & 284.2 & -0.8 & 399.7 & 207.9 & 532.7 \\
PAn3 & 284.4 & -0.6 & 400.0 & 207.6 & 532.5 \\
PAn4 & 283.6 & -1.4 & 400.3 & 208.3 & 532.8 \\
PAn5 & 284.4 & -0.6 & 400.6 & 207.5 & 532.5 \\
\hline
\end{tabular}

The correction factors of sensitivities for each XPS peak have been previously obtained from various standard samples (9). The relative integrated intensities were corrected by this factor. The concentration ratios of the respective elements obtained in this manner are summarized in Table 2.
Table 2 Relative compositions of each element

\begin{tabular}{cccc}
\hline polyaniline & $\mathrm{Cl} / \mathrm{N}$ & $0 / \mathrm{Cl}$ & $\mathrm{C} / \mathrm{N}$ \\
\hline PAn1 & $0.5_{5}$ & $4.5_{4}$ & $8.9_{2}$ \\
PAn2 & $0.3_{2}$ & $5.0_{8}$ & $8.0_{2}$ \\
PAn3 & 0.76 & $3.6_{3}$ & $7.0_{2}$ \\
PAn4 & $0.8_{6}$ & $3.7_{4}$ & $11.0_{7}$ \\
PAn4 & $0.7_{8}$ & 4.75 & $13.7_{2}$ \\
PAn5 & 0.68 & 4.25 & $9.0_{8}$ \\
\hline
\end{tabular}

A PAn4 measured after 90 minutes. 


\subsection{Separation of $N(1 s)$ spectrum}

The N(1s) spectra of the samples, as shown in Figure 1, split into two peaks. The peak separation was made by a CURVE RESOLVER attached to the ESCA650B using a standard band shape of Au(4f) peak. Peak intervals, line widths and relative intensity ratios of the separated nitrogen peaks are summarized in Table 3 .

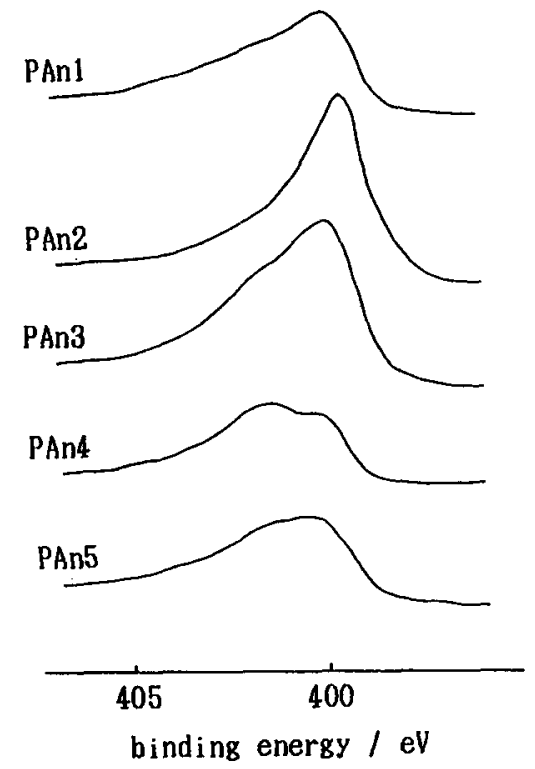

Figure 1 Observed N(1s) spectra of each sample.

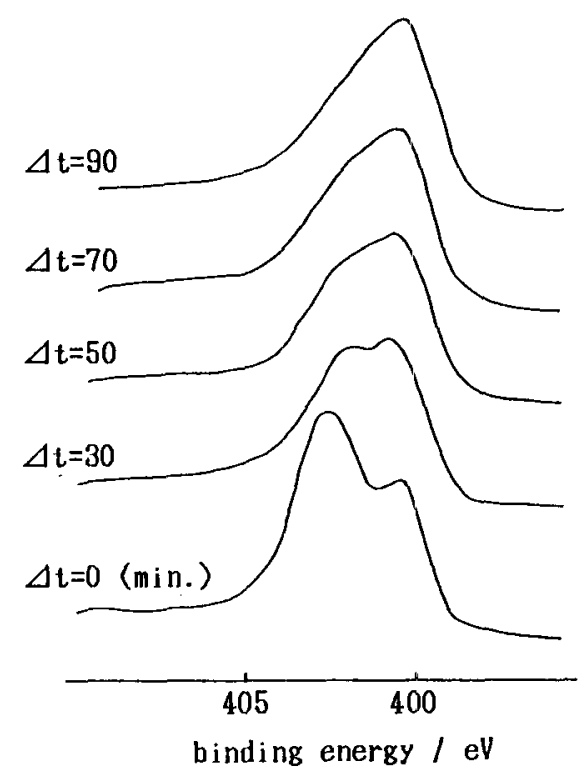

Figure 2 Changes of $N(1 \mathrm{~s})$ spectrum during the measurement for reduced PAn in aqueous solution (PAn4).

Table 3 Spectral parameters and intensity ratio of $N(1 s)$

\begin{tabular}{|c|c|c|c|c|}
\hline polyaniline & $\begin{array}{l}\text { peak } \\
\text { interval }\end{array}$ & $\begin{array}{l}\text { peak } \\
\text { Nhion }\end{array}$ & $\begin{array}{l}\text { idth of } \\
N_{\text {low }}(\mathrm{eV})\end{array}$ & $\begin{array}{l}\text { intensity ratio of } \\
N_{n i g h} /\left(N_{n i} \text { on }+N_{1} \text { ow }\right)\end{array}$ \\
\hline $\begin{array}{l}\text { PAn1 } \\
\text { PAn2 } \\
\text { PAn3 } \\
\text { PAn4 } \\
\text { PAn4 } \\
\text { PAn5 }\end{array}$ & $\begin{array}{l}1.4 \\
1.4 \\
1.4 \\
2.2 \\
1.4 \\
1.4\end{array}$ & $\begin{array}{l}5.2 \\
5.2 \\
5.2 \\
4.0 \\
5.2 \\
5.2\end{array}$ & $\begin{array}{l}2.6 \\
2.6 \\
2.6 \\
2.3 \\
2.6 \\
2.6\end{array}$ & $\begin{array}{l}0.5_{5} \\
0.3_{5} \\
0.69 \\
0.7_{5} \\
0.6_{6} \\
0.5_{2}\end{array}$ \\
\hline
\end{tabular}

A PAn4 measured after 90 minutes.

\section{3 Spectrum change during the measurement of PAn4}

In the case of PAn4 sample, the band shape of the $N(1 \mathrm{~s})$ spectrum changed with lapse of time during the measurement. These changes in the $N(1 s)$ spectra during the measurement (time=0-90 minutes) are shown in Figure 2. X-ray radiation was applied to the sample only during the measurement. The composition of each element in the 
polymer also changed during the measurement. The relative compositions of the components measured after 90 minutes are also listed in Tables 2 and 3.

\section{DISCUSSION}

\section{1 Non-aqueous system}

From our previous results (6), the reduced and oxidized PAn in the non-aqueous solution, PAn2 and PAn3, are considered to be in fully discharged or charged states, respectively. The $\mathrm{Cl} / \mathrm{N}$ ratio in Table 2 corresponds to $\mathrm{ClO}_{4}{ }^{-} /$(aniline unit) ratio in the polymer, considering the elemental composition of PAn. Comparing the $\mathrm{Cl} / \mathrm{N}$ ratios of PAn1, PAn2 and PAn3 in Table 3, it is clear that the $\mathrm{Cl} / \mathrm{N}$ ratio increases with an increase in the oxidation level of the polymer. This suggests that the redox of PAn in the non-aqueous solution is accompanied by anion doping, which is in good agreement with our previous results (6). As regards this point, the PAn redox process is similar to that of polypyrrole as previously reported (10). However, a characteristic feature of PAn is the fact that the high energy band ratio, $\mathrm{N}_{\mathrm{high}} /\left(\mathrm{N}_{\mathrm{high}}+\mathrm{N}_{\text {low }}\right)$, in $\mathrm{N}(1 \mathrm{~s})$ spectrum increases as the polymer is oxidized, as shown in Table 3. Considering the structural formula of $\mathrm{PAn}_{\text {s }}$ the $\mathrm{N}_{\text {high }}$ and $\mathrm{N}_{\text {low }}$ peaks were assigned to cationized nitrogen $\left(\mathrm{N}^{+}\right)$and neutral nitrogen $(\mathrm{N})$, respectively. Therefore the increase in the $N_{\text {high }}$ ratio on oxidation suggests a corresponding increase of the $\mathrm{N}^{+}$component in the polymer. It is also interesting that the increase in the $\mathrm{Cl} / \mathrm{N}$ ratio on oxidation corresponds to the increase in the $\mathrm{N}_{\text {high }} /\left(\mathrm{N}_{\text {high }}{ }^{+\mathrm{N}_{1}}\right.$ ow $)$ ratio. This result indicates that the redox of PAn in the non-aqueous solution is accompanied by the redox of the nitrogen atom whose positive charge is compensated by $\mathrm{ClO}_{4}^{-}$anion. Thus an idealized redox mechanism of PAn in the non-aqueous solution can be described as shown in Figure 3. According to the scheme, an ideal rechargeable electron number is 1 electron/(one aniline unit), $\mathrm{e}^{-/ A n}$, since PAn contains one nitrogen atom in each aniline unit. However, an actually rechargeable electron number of about $0.8 \mathrm{e}^{-/ \text {An was obtained in }}$ our previous studies $(4,6)$. This rechargeable electron number is much larger than those of polypyrrole or polythiophene, about 0.3 electron monomer unit for both polymers, as determined in our previous study (4). This comparatively large rechargeable electron number in PAn is attributed to be due to the "nitrogen redox mechanism" illustrated in Figure 3.

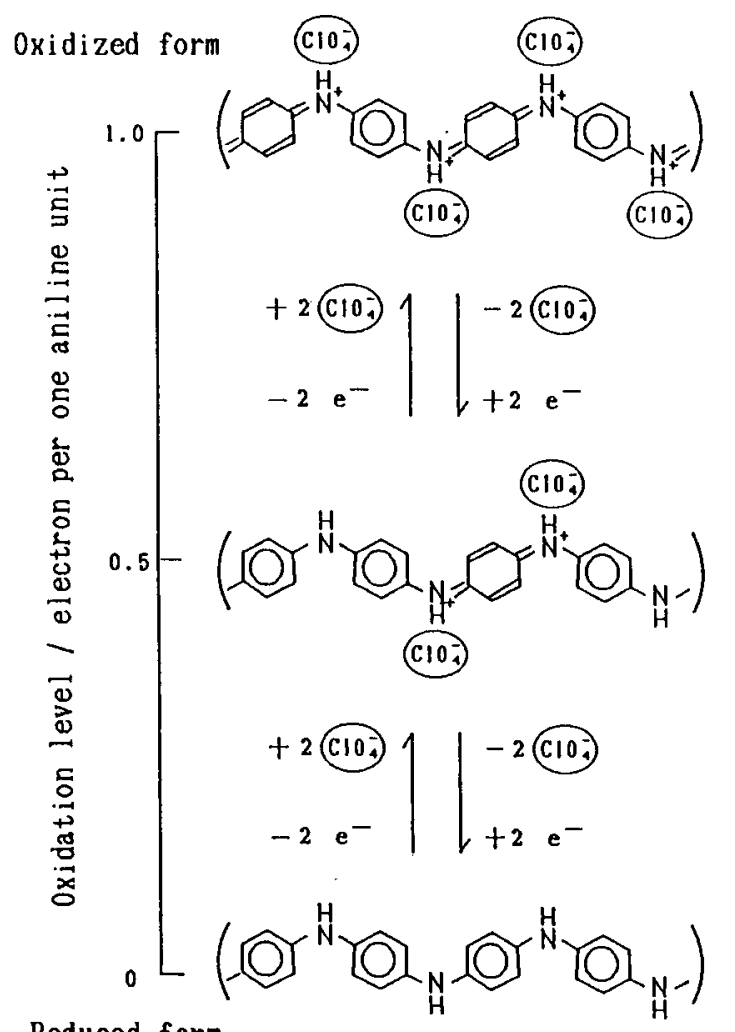

Reduced form

Figure 3 Redox scheme of PAn in non-aqueous solution. 


\section{2 Aqueous system}

As shown in Table 2 and Table 3 , the $\mathrm{Cl} / \mathrm{N}$ ratio and the $\mathrm{N}_{\text {high }} /\left(\mathrm{N}_{\text {high }}+\mathrm{N}_{\text {low }}\right)$ ratio of PAn4 remarkably increases, as compared with those of PAn1. The result suggests that the content of the cationized nitrogen and the anion in the polymer increase on reduction in the aqueous solution, as opposed to the result for the non-aqueous solution. The band shape of the N(1s) spectrum of PAn4, however, changes during the measurement, as shown in Figure 2. The high energy band, which is clearly observed at the initial stage, subsequently diminishes and becomes to a shoulder of the low energy band. The band shape of the $N(1 \mathrm{~s})$ spectrum after 90 minutes resembles that of PAn1. The $\mathrm{Cl} / \mathrm{N}$ ratio and the $\mathrm{N}_{\mathrm{high}} /\left(\mathrm{N}_{\mathrm{high}}+\mathrm{N}_{l o w}\right)$ ratio of PAn4 decrease and approach to those of PAn1 during the measurement, as shown in Table 2 and Table 3. These results indicate that PAn4 is gradually oxidized by $\mathrm{ClO}_{4}{ }^{-}$anions doped in the film. A high anion content in PAn4 must promote the oxidation of the polymer. The - instability of PAn4 in the XPS measurement made it difficult to analyze an "asreduced form" of PAn4 in detail. The spectral changes shown in Figure 2, however, indicate that the $\mathrm{Cl} / \mathrm{N}$ ratio and the $\mathrm{N}_{\text {high }} /\left(\mathrm{N}_{\mathrm{high}}+\mathrm{N}_{10 \mathrm{w}}\right)$ ratio of PAn4 in the earlier stage of the measurement are expected to have larger values. Thus it is still more obvious that cationized nitrogen together with perchlorate anion increases on reduction in the aqueous solution. These results clearly indicate that the redox mechanism of PAn in the aqueous solution is different from that in the non-aqueous solution. MacDiarmid et al. have proposed a redox and acid-base reaction mechanism in aqueous system (1), as illustrated in Figure 4. According to the scheme, no change should occur in the $\mathrm{Cl} / \mathrm{N}$ ratio or the $\mathrm{N}_{\text {high }} /\left(\mathrm{N}_{\text {high }}+\mathrm{N}_{\text {low }}\right)$ ratio when the polymer is reduced. The result obtained in the present study, however, shows that chemical protonation is promoted when the polymer is reduced. Thus the chemical protonation level is determined not only by the $\mathrm{pH}$ of the solution but also by the oxidation level of PAn. This is attributable to a stereochemical effect of the reduced form with a non-planar conformation.

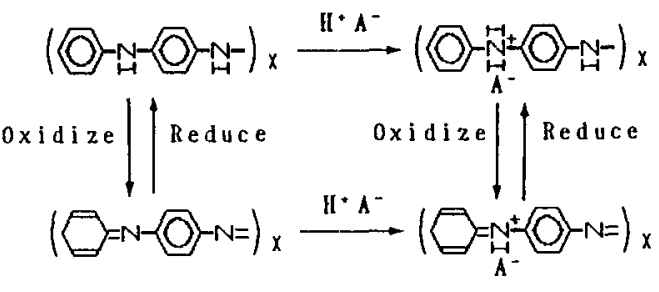

Figure 4 Redox and acid-base reaction scheme of PAn in aqueous solution(1).

In the case of PAn5, as shown in Tables 2 and 3, little change was observed in the $\mathrm{Cl} / \mathrm{N}$ and $\mathrm{N}_{\mathrm{high}} /\left(\mathrm{N}_{\mathrm{high}}+\mathrm{N}_{\mathrm{low}}\right)$ ratios, as compared with those of PAn1. This result indicates that the structure of PAn5 is almost the same as that of PAn1. It has been found, however, that PAn5 is immediately decomposed to quinone (11). Thus it is difficult to discuss in detail the structure of PAn5 from these XPS data.

\section{CONCLUSION}

The chemical conformation and the redox mechanism of PAn were discussed in terms of XPS measurements. The oxidation state of the nitrogen atom and the $\mathrm{ClO}_{4}^{-}$anion content in the polymer during the redox of PAn were observed by the XPS analysis. In the non-aqueous solution, the amount of the cationized nitrogen and the perchlorate anion in the polymer increases on oxidation. This indicates that the redox of PAn in the non-aqueous solution is accompanied by the redox of the nitrogen atoms in the polymer. The high discharge capacity of the PAn cathode is attributed to the 
characteristic redox mechanism which has not been observed in other conducting polymers.

The XPS data showed another interesting result that the chemical protonation of the polymer is promoted on reduction in the aqueous solution. This indicates that the oxidation level of PAn affects its acid-base equilibrium in the aqueous solution.

Following these conclusions, the redox of the nitrogen in the polymer, which was observed by the XPS analysis, characterizes the chemical and the electrochemical properties of PAn.

\section{REFERENCES}

1) A. G. MacDiarmid, S. L. Mu, N. L. D. Somasiri and W. Wu, Mol. Cryst. Liq. Cryst. $\underline{121}, 187$ (1985)

2) A. Ki tani, M. Kaya, Y. Hiromoto and K. Sasaki, Denki Kagaku, 53, 592 (1985)

3) E. M. Genies, M. Lapkowski, C. Santier and E. Vieil, Synth. Met. , 18, 631 (1987)

4) F. Goto, K. Abe, K. Okabayashi, T. Yoshi da and H. Morimoto, J. Power Sources, 20 , 243 (1987)

5) Y. Furukawa, F. Ueda, Y. Hyodo, I. Harada, T. Nakaj ima and T. Kawagoe, MacromoI. , 21, 5 (1988)

6) K. Okabayashi, F. Goto, K. Abe and T. Yoshida, Synth. Met, 18 , 365 (1987)

7) E. M. Genies, A. A. Syed and C. Tsintavis, Mol. Cryst. Liq. Cryst. 121,181 (1985)

8) P. H. Snauwaert, R. Lazzaroni, J. Riga and J. J. Verbi st, Synth. Met. , 16, 245 (1986)

9) Obtained by M. Tada for the spectrometer used here.

10) A.F. Diaz, J. I. Castrill lo, J. A. Logan and W. Y. Lee, J. Electroanal. Chem. , 129, 115 (1981)

11) T. Kobayashi, H. Yoneyama and H. Tamura, J. Electroanal. Chem. , $177,293(1984)$ 